\title{
The Perils of Tax Smoothing: Sustainable Fiscal Policy with Random Shocks to Permanent Output
}

\author{
Evan TANNER - IMF, Washington (etanner@imf.org) \\ Kevin CAREY - World Bank, Washington (kcarey@worldbank.org) ${ }^{* *}$
}

\begin{abstract}
If permanent output is uncertain, tax smoothing can be perilous: both debt levels and tax rates are difficult to stabilize and may drift upwards. One practical remedy would be to target the debt. However, our simulations confirm that such a policy would require undesirably volatile fiscal adjustments and may inhibit countercyclical borrowing. An alternative would be to link the primary surplus not only to the debt ratio (like tax smoothing) but also to its volatility, thus preempting further adjustments while gradually reducing the debt.
\end{abstract}

\section{Introduction}

According to a recent report by the International Monetary Fund's Independent Evaluation Office (IMF/IEO; International Monetary Fund, 2003), fiscal components of Fund programs are typically plagued by erroneous (often optimistic) output forecasts. ${ }^{1}$ In addition, the report suggested that the magnitude of an initial fiscal adjustment was often not clearly justified in terms of long-run fiscal debt sustainability, and the rationale for subsequent program revisions is often unclear.

Most would agree that the goal of a well-intentioned policy adviser (from the Fund or elsewhere) should be to design a fiscal policy that is sustainable in the long run but not excessively harsh during temporary downturns. Regarding the latter criteria, the use of automatic fiscal stabilizers, including borrowing over the business cycle, is generally regarded to be desirable: if a government is permitted to borrow during downturns, it may be able to reduce the volatility of tax rates, expenditures, and aggregate activity.

Moreover, given the uncertainties surrounding output growth, designing such a fiscal policy is a daunting task. To successfully borrow during economic downturns, a government needs to do more than simply adhere to Rogoff's (2003) common-sense admonition to save during upturns. Such a policy requires that the government esti-

* This paper was adapted from an IMF working paper. It should not be interpreted as representing the views of the IMF or the World Bank. The views expressed in paper are those of the authors and do not necessarily represent those of the IMF, the World Bank or the policies of either institution.

** E. Tanner (corresponding author) is a Senior Economist in the Western Hemisphere Division of the IMF Institute; K. Carey is a Senior Country Economist for the Gulf Cooperation Council Countries, Middle East and North Africa Region. We acknowledge useful comments by Eza Al-Zein, Adolfo Barajas, Luis Catão, Enzo Croce, Mercedes da Costa, Lennart Erickson, Hugo Juan-Ramón, André Santos, and Irina Yakadina. Special thanks are due to Jacques Miniane, who shared his knowledge of learning models. All remaining errors are our responsibility.

${ }^{1}$ On the issue of optimistic output forecasts, see also (Juhn, Loungani, 2002). 
mate permanent output - explicitly or implicitly - since the government's spending capacity is determined by the permanent (not current) tax base.

The quality of permanent output forecasts may depend on the technical expertise or the underlying intentions of the policymaker. Alternatively, permanent output may be characterized by unpredictable, persistent shocks. In this case, forecast errors for permanent output are an inherent feature of the output process itself, not a reflection the fiscal authority's expertise or intentions.

What are the implications for debt outcomes when it is difficult to forecast permanent output? To address this question, we consider several alternative fiscal rules in an environment where output shocks are partly composed of a permanent (random-walk) component. Importantly, the government is unable to distinguish between permanent and temporary components. However, the government knows that both kinds of shocks are normally distributed, the mean of both kinds of shocks is zero, and it knows the variances of both kinds of shocks (both absolutely and relative to one another). Thus, an informational imperfection arises from the fact that the government cannot distinguish between permanent and temporary shocks. That is, the government faces a "signal extraction" problem similar to one originally proposed by Muth (1960) (see also (Harvey, 1989), and (Miniane, 2004)).

A recurrent theme in this paper is that of a fiscal objective function. McCallum (2000) and others have suggested that a rules-based policy regime reflects the maximization by the authority of an objective function with a time-invariant (not period-by-period) perspective. This echoes Lucas (1976) and Kydland and Prescott (1977), who advocate rules with "good operating characteristics [...] (that are) simple and easily understood, so it is obvious when a policy maker deviates from the policy".

Our benchmark regime resembles the tax smoothing model proposed by Barro (1979). The essential element of such a policy is that rates are optimally aligned one-to-one with total expenditures (primary plus interest). Such a regime closely resembles the canonical debt sustainability framework widely used by policy makers (see (Blanchard et al., 1990), (Burnside, 2005, Ch. 3)); it is often interpreted to also be a debt stabilization framework (International Monetary Fund, 2003b).

This framework uses a common-sense analogy with the permanent income hypothesis of consumer behavior (one that Barro himself emphasized). As in Sargent's (1987, pp. 385-88) extension to Barro's (1979) framework, the deadweight losses of taxation are reflected in a linear quadratic collection cost function. ${ }^{2}$ Since primary expenditures are exogenous, tax rates respond to permanent changes in the public budgetary burden. If output shocks are temporary, governments should borrow over the business cycle rather than adjust taxes, and government debt optimally fluctuates countercyclically around a deterministic mean.

However, our analysis reveals that it can be difficult to stabilize either the debt ratio or the tax rate if there are permanent shocks to output. Instead, under

\footnotetext{
${ }^{2}$ The idea of tax smoothing continues to receive attention in the optimal fiscal policy literature; see, for example (Kingston, 1991), (Lloyd-Ellis, Zhan, Zhu, 2005), and (Fisher, Kingston, 2005). Other recent papers that use a loss function to approximate underlying consumer welfare include Benigno and Woodford (2003) and Angeletos (2003). By contrast, a paper that directly maximizes consumer utility is Chari, Christiano, and Kehoe (1994); they also introduce large capital levies in an initial period to raise consumer welfare (an element absent from our paper).
} 
a tax smoothing regime, fiscal policy takes on the unpredictable flavor described in the IMF/IEO report: both tax rates and debt ratios can be volatile and may even drift upward from their initial values over time. Such unpredictability relates to "debt intolerance" discussed by Reinhart, Rogoff, and Savastano (2003): even at low levels of debt, markets may have difficulties distinguishing permanent from transitory fluctuations in the debt ratio, and they may doubt that a required adjustment will take place.

For a fiscal authority that faces such difficulties, we consider two remedies. First, we consider a debt targeting (DT) regime similar to one found in the European Union and elsewhere: the fiscal authority adjusts the primary surplus (taxes) when there is a permanent gap between the desired and actual level of debt. As our simulations confirm, such a regime will stabilize the debt, but at the expense of more tax volatility.

Second, we incorporate a precautionary element into fiscal policy: the primary surplus is linked not only to the level of debt (as under tax smoothing), but also to the variability of the debt ratio. ${ }^{3}$ If the variability of the tax burden rises, the authority optimally increases the primary surplus. Beneath such a rule lies an objective to avoid future fiscal adjustments for all but the most unfavorable circumstances (not unlike a value-at-risk approach). For illustrative purposes, we consider a constant absolute risk aversion (CARA)/hyperbolic objective function, extending the representative consumer analogy, following Caballero's (1990) work on precautionary saving. An objective function of this nature is consistent with recent stochastic approaches to debt sustainability - Monte Carlo simulations and "fan charts" - proposed by Hoffmaister et al. (2001), Garcia and Rigobon (2004), Hostland and Karam (2006), Celasun, Debrun, and Ostry (2006), and Tanner and Samake (2008).

Under the simulated precautionary regime (PR), the initial primary surplus is modestly higher than under the alternatives, both tax rates and the debt ratio fall over time. For cases where the permanent component to output shocks is important, the precautionary regime provides a smoother path of taxes than under debt targeting.

The remainder of the paper is organized as follows. Section 2 presents the economic environment. Section 3 discusses the loss function associated with tax smoothing. Section 4 discusses some additional aspects of tax smoothing. Section 5 presents a debt targeting regime. Section 6 presents a precautionary regime. Section 7 presents simulations. Section 8 concludes.

\section{The Economic Environment}

In this paper, we will compare several alternative fiscal regimes. All share a common economic environment with three key elements: the output process, the government's intertemporal budget constraint, and the sequencing of fiscal policy decisions in any period.

The output process. Output $Y$, is the sum of permanent and transitory components. It follows a "random-walk-plus-noise" model (see (Harvey, 1989; p. 102)):

\footnotetext{
${ }^{3}$ Other recent work on fiscal policy that features a precautionary element includes the International Monetary Fund's (2003) stress test framework, Value-at-Risk (VaR) methodologies like that of Kopits and Barnhill (2003), and the discussion of the fiscal authority's role as a "tormented insurer" found in (Mendoza, Oviedo, 2004).
} 


$$
\begin{aligned}
& Y_{t}=Y_{t}^{P}+\varepsilon_{t} \\
& Y_{t}^{P}=Y_{t-1}^{P}+\eta_{t}
\end{aligned}
$$

where $Y_{t}^{P}$ is permanent output. The permanent component is a random walk with shock $\eta_{t}$. The transitory component $\varepsilon_{t}$ is pure noise. The shocks to the permanent and transitory component are uncorrelated at all leads and lags. The separate components are never observed. The "signal-to-noise" ratio $q=\operatorname{var}\left(\eta_{t}\right) / \operatorname{var}\left(\varepsilon_{t}\right)$ is assumed to be known. Only the sum of three elements $\left(Y_{t-1}^{P}+\varepsilon_{t}+\eta_{t}\right)$ is observed - not the individual elements.

In the well-known signal extraction problem, an economic agent attempts to distinguish permanent and temporary components. The recursive estimate of permanent output at time $t$ conditional on information available at time $t-1, \hat{Y}^{P}{ }_{t \mid t-1}$, is:

$$
\hat{Y}_{t \mid t-1}^{P}=(1-\alpha) \hat{Y}_{t-1 \mid t-2}^{P}+\alpha Y_{t-1}
$$

where $\alpha$, derived from a least-squares optimization problem, is a function of the signal-to-noise ratio, $q: \alpha=q+\left[q^{2}+4 q\right]^{0.5} /\left[2+q+\left[q^{2}+4 q\right]^{0.5}\right]$ (see (Muth, 1960), (Harvey, 1989), (Miniane, 2003)). Notice that information acquired in a period is only useful for forecasting in the following period.

The government budget constraint. In any period, the government's constraint in constant prices is:

$$
B_{t=1}(1+r)-P S_{t}=B_{t}
$$

where $B$ is real debt and $P S$ is the real primary surplus (tax revenue $T$ minus primary government expenditures $G$ ). As a ratio to output, the ex post budget constraint is:

$$
b_{t-1} \theta_{t}-p s_{t}=b_{t}
$$

where $b$ is the ratio of government debt to output $(Y), \theta$ is the ex post growth adjusted discount factor $(1+r) /(1+\lambda), \lambda_{t}=\left(Y_{t} / Y_{t-1}-1\right)$ is the realized growth rate of real output, and $p s_{t}$ is the primary surplus ratio to output. The intertemporal budget constraint is obtained by successive substitution of (1) over an infinite horizon:

$$
\underset{t=0}{\infty} \underset{t=0}{\infty} \underset{t \rightarrow \infty}{\infty} \underset{t=0}{\infty}
$$

The transversality (or "no-Ponzi game") condition is:

$$
\lim _{t \rightarrow \infty} b_{t} /(1+r)^{t-1}=0
$$

Equation (4b) says that the limiting discounted value of government liabilities cannot differ from zero. ${ }^{4}$

The sequence of fiscal policy decisions. Common to all regimes is an assumed sequence that reflects some important aspects of fiscal policymaking. In the initial

\footnotetext{
${ }^{4}$ Note that trend growth of output is assumed to be zero. The model can be modified to include a drift term in permanent output.
} 
period $(t=1)$ the government inherits debt level $B_{0}$. Likewise, the debt level $B_{t-1}$ is known at the beginning of every subsequent period.

The government must make certain decisions at the beginning of each period $(t=1,2, \ldots)-$ before the output shocks are realized. We assume that governments control the level of spending. They make commitments at the beginning of the period, and they fulfill their commitments through the end of the period. We also assume that our government wishes to smooth its expenditures in the sense that it programs a constant proportion $\gamma$ of forecasted permanent output in period $t$ conditional on information in time $t-1$ (that is, before output is realized $\hat{Y}^{P}{ }_{t \mid t-1}$ ). That is,

$$
G_{t}=\gamma \hat{Y}_{t \mid t-1}^{P}
$$

And, at the beginning of each period the government also chooses the tax rate $\tau$ which is levied on realized output $Y_{t}{ }^{5}$ As discussed below, depending on which regime is chosen, $\tau^{i}$ is chosen, where $i$ designates the chosen regime. Typically, a regime reflects some relationship between tax rate $\tau_{t}^{i}$, the fixed primary expenditure ratio $\gamma$ and interest payments $r b_{t-1}$.

\section{Tax Smoothing (TS) under a Linear Quadratic Loss Function}

Ideally, fiscal regimes should reflect an underlying objective function. In this paper, the government's objective is similar to one proposed by Barro (1979): the government is assumed to minimize tax collection costs. Assuming exogenous values for the primary expenditure ratio $\gamma$, the initial debt ratio $b_{-1}$, and the real interest rate $r$, and the current period estimate of permanent output $\hat{Y}_{t \mid t-1}^{P}$, the government chooses a path of tax rates $\tau_{t}$ that minimizes the discounted expected loss function:

$$
\sum_{t=0}^{\infty} E_{t} \Phi\left(\tau_{t}\right) /(1+\varphi)^{t}
$$

where $E_{t}$ is the conditional expectations operator and $\varphi$ is the government's rate of time preference, subject to constraints (4a) and (4b) and the framework for expenditure decisions (5). In this section, we consider a specific functional form, namely the linear quadratic form, similar to one found in Sargent's (1987, pp. 385-88) extension of Barro's model:

$$
\Phi\left(\tau_{t}\right)=\phi \tau_{t}^{2}
$$

In this case, for $\varphi=r$, the first order condition in any period $t$ is $2 \phi \tau_{t}=\varpi, \forall t$ ( $\varpi=$ Lagrange multiplier), and thus the Euler equation implies that $\tau_{t}=E_{t}\left(\tau_{t+1}\right), \forall t$. In our context, the government seeks to maintain a constant expenditure share of permanent output. Thus, substituting the Euler equation into ex ante budget constraint (4a) yields the following policy rule:

$$
\tau_{t}^{T S}=\gamma+r b_{t-1}^{T S}
$$

\footnotetext{
${ }^{5}$ More precisely, since there is no time inconsistency in this model, optimization is assumed to take place at $t=0$; thereafter, the government simply executes decisions based on policy functions calculated at $t=0$ and realizations of the random variables.
} 
or all $t$, where $b_{t-1}{ }^{T S} \equiv r B_{t-1}{ }^{T S} / \hat{Y}_{t \mid t-1}^{P}$ is the debt level in the previous period scaled by expected permanent output. (Equivalently, the rule says that the expected primary surplus should be $\left.p s_{t}^{T S}=r B_{t-1} / \hat{Y}^{P}{ }_{t \mid t-1}\right)$. Ex post, the debt level $B_{t}$ is:

$$
B_{t}^{T S}=B_{t-1}^{T S}\left(1+r-r \Psi_{t}\right)+\gamma\left[\hat{Y}_{t \mid t-1}^{P}-Y_{t}\right]
$$

where $\Psi_{t} \equiv Y_{t} / \hat{Y}_{t \mid t-1}^{P}$. And, the ex post debt ratio $b_{t}\left(\equiv B_{t} / Y_{t}\right)$ evolves according to:

$$
b_{t}^{T S}=b_{t-1}^{T S}\left(Y_{t-1} / Y_{t}\right)\left(1+r-r \Psi_{t}\right)+\gamma\left[\Psi_{t}^{-1}-1\right]
$$

Thus, the tax smoothing framework reflects a standard logic: temporary changes in government spending are financed by temporary debt issue, while permanent spending changes are matched one to one with tax rate changes. Importantly, equations (9) and (10) reveal that if there are no errors in forecasting permanent output ( $\Psi=1$ ) the debt ratio (relative to permanent output) is stabilized; this feature is widely recognized (see, for example (International Monetary Fund, 2003b)). The tax smoothing regime closely resembles the sustainability frameworks of Blanchard et al. (1990), Talvi and Végh (2000), and Burnside (2005).

\section{Does a Tax Smoothing Regime Stabilize the Debt?}

Equations (9) and (10) also reveal how debt fluctuations stem from errors in forecasting permanent output, in both ratio form $\Psi_{t}$ and difference form $\left[\hat{Y}_{t \mid t-1}^{P}-Y_{t}\right]$. In this section, we discuss why it may be difficult to stabilize the debt under a tax smoothing regime.

It has been well known since Barro (1979) and Sargent (1987) that both debt and taxes can follow random walks. However, in their models, the random walk stems from the assumption that there are random shocks to expenditures (that is, wars). By contrast, we assume that the authority aims to keep the expenditure ratio constant.

However, if there is a substantial permanent component to output shocks $(\operatorname{var}(\eta)$ large relative to $\operatorname{var}(\varepsilon))$, debt and taxes may also drift substantially from their origin. Moreover, the random walk in the debt ratio (and implicitly, the tax rate) may contain an upward drift. This point may be illustrated by a simple example. Suppose that output follows a random walk $(q=\infty)$, and that $Y_{0}=100$. Assume also that both the tax rate and ex ante expenditure ratio are set at $20 \%(\tau=\gamma=0.2)$, with no initial debt. At the beginning of period 1 - before that period's shock - expected permanent output $\hat{Y}_{1 \mid 0}^{P}=100$. If expectations are correct, ex post $Y^{P}{ }_{1}=100$ and the deficit equals zero - both as a level and as a ratio to permanent output $Y^{P}$. Alternatively, consider symmetric shocks of \pm 5 units. For the pessimistic case $Y^{P_{1}}=105$, the surplus as a ratio to output is $0.952 \%([21-20] / 105)$. For the optimistic case $Y^{P}=95$, that (deficit) ratio is $-1.053 \%$ of output ([19-20]/95). Thus, the mean surplus ratio-to-output is $-0.033 \%$ (deficit); the shocks do not exactly cancel out but instead exhibit a deficit bias. Alternatively, we may verify more formally that there is an upward drift to debt. First, rewrite (10) as:

$$
b_{t}^{T S}=b_{t-1}^{T S}+b_{t-1}^{T S} r\left(1-\Psi_{t}\right)+\gamma\left[\Psi_{t}^{-1}-1\right]
$$


Next, by appealing to Jensen's Inequality, it can be shown that the two error terms $\left(1-\Psi_{t}\right)$ and $\left[\Psi_{t}^{-1}-1\right]$ may have positive (rather than zero) means. ${ }^{6}$

Seen either way, this result helps illustrate how the debt ratio might drift upwards under a TS regime - even if the policymaker does not intend it to do so. Simulations (discussed below) will reveal that such an upward drift is more modest in cases where permanent shocks are relatively unimportant. But, such a drift is more apparent as permanent shocks become more important relative to temporary shocks $(\operatorname{var}(\eta)$ grows relative to $\operatorname{var}(\varepsilon))$.

Even for the extreme case with only temporary shocks $(\operatorname{var}(\eta)=0, \operatorname{var}(\varepsilon)>0)$, there will be ex ante permanent changes to the debt under this regime. To see this, note that an adverse shock in the initial period will cause a one-period deficit - and an increase in the debt. Since the expected value of all future shocks is zero, the debt has risen permanently ex ante. (Ex post, however, simulations of such a case yield debt outcomes that are distributed around the initial mean.)

Also, under intermediate cases of (1a)-(1b) wherein both $\operatorname{var}(\varepsilon)$ and $\operatorname{var}(\eta)$ are nonzero, under a TS regime, any shock - permanent or temporary - will cause persistent build-ups / drawdowns of debt. Indeed, as simulations later in the paper show, debt levels at the end of $J$ periods are more uncertain if there are both temporary and permanent shocks to output $\operatorname{var}(\eta), \operatorname{var}(\varepsilon)$ both nonzero than at either of the two polar extremes $(\operatorname{var}(\eta)=0$, or $\operatorname{var}(\varepsilon)=0)$. This happens because agents do not know whether a given shock is temporary or permanent until some time after the shock has occurred.

To illustrate, assume that in period 1 the inherited debt stock is zero $\left(b_{0}=0\right)$ and permanent output, known before the first period shock, is $Y^{P_{0}}$. Assume also that the first period shock (the sum of the unobserved components) is adverse: error $_{1}=$ $=\varepsilon_{1}+\eta_{1}<0$. Finally, assume that after period 1 there are no additional shocks $\left(\right.$ error $\left._{t}=0, t=2,3,4 \ldots\right)$.

Consider now two polar cases of shocks that are fully permanent $\left(\right.$ error $\left._{1} \equiv \eta_{1}\right)$ and fully temporary $\left(\right.$ error $\left._{1} \equiv \varepsilon_{1}\right)$. In either case, the government runs a period 1 deficit equal to $\gamma\left[Y^{P}{ }_{0}-Y_{1}\right]$. However, if the adverse shock is fully permanent (error ${ }_{1} \equiv$ $\equiv \eta_{1}$ ), permanent output will be overestimated in period 1 by the amount $\hat{Y}_{1 \mid 1}^{P}-Y^{P}{ }_{1}=$ $=\eta_{1}(1-\alpha)>0$. Since the estimate of permanent output in successive periods is a recursion, the error will persist and die out gradually. Accordingly, in subsequent periods, the government will "overspend" by the amount $\gamma\left[\hat{Y}^{P}{ }_{t}-Y^{P}{ }_{t}\right]-$ a persistent deficit and a permanent accumulation of debt.

By contrast, if the adverse shock is fully temporary (error $\left.{ }_{1} \equiv \varepsilon_{1}\right)$, permanent output will be underestimated in period 1 by the amount $\hat{Y}^{P}{ }_{1 \mid 1}-Y^{P}{ }_{1}=-\alpha \varepsilon_{1}<0$. Again, noting the recursive nature of permanent output forecasts, the underestimate will die out only gradually. Accordingly, in the subsequent periods, the government will "underspend" by the amount $-\mathcal{H}\left[\hat{Y}^{P}{ }_{t}-Y^{P}{ }_{t}\right]-$ a persistent surplus/debt drawdown.

\footnotetext{
${ }^{6}$ Specifically, note first that $\left(1-\Psi_{t}\right)=\left[\hat{Y}_{t \mid t-1}^{P}-Y_{t}\right] / \hat{Y}_{t \mid t-1.1}^{P}$ Next, we define $Z_{t} \equiv\left[\hat{Y}_{t \mid t-1}^{P}-Y_{t}\right]$, where $E(Z)=0$, and $f(Z)=Z / \hat{Y}^{P}$. Since the partial derivatives are $\partial Z / \partial \hat{Y}^{P}=-\left(\hat{Y}^{P}\right)^{-2} . \partial^{2} Z / \partial \hat{Y}^{P 2}=2\left(\hat{Y}^{P}\right)^{-3}>0, f(Z)$ is a convex function. Consistent with Jensen's Inequality, if $f(Z)$ is convex, $E(f(Z)) \geq f(E(Z))$ and, since $f(E(Z))=0$, $E(f(Z)) \geq 0$. A symmetric proof holds for $\left[\Psi_{t}^{-1}-1\right]$.
} 
The potential for large and permanent shifts in debt levels, even when policy makers are well-intentioned, brings to mind the "debt intolerance" suggested by Reinhart, Rogoff, and Savastano (2003). Large and permanent shifts to debt levels will require large adjustments. Markets may have difficulties distinguishing permanent from temporary shocks to government debt. Moreover, markets may doubt that the required adjustment will take place. In these cases, a crisis of "debt intolerance" may take place - even at relatively low levels of debt.

The question arises as to whether the government could have other mechanisms besides distortionary taxation for dealing with uncertainty. In the optimal fiscal policy literature, some (Lucas, Stokey, 1983) have suggested that the public sector could issue state-contingent assets. However, such contingencies on debt need not be explicitly specified. Instead, according to the fiscal theory of the price level, unanticipated inflations will do the job under a "non-Ricardian" regime - one in which the government does not explicitly adjust the primary surplus (Cochrane, 1998), (Woodford, 2001), (Chari, Christiano, Kehoe, 1994), and (Hall, Krieger, 2002).

Real-world examples of explicit state-contingent government debt are rarely found. And, neither explicit default nor unanticipated inflation appears to be widely embraced as optimal policy in the real world. Rather, most governments would like to avoid such events.

Several kinds of market imperfections may help to explain this disconnect between theory and reality. First, there may be important informational asymmetries (including moral hazard) in the conduct of fiscal policy: the government itself has control over spending levels. Second, in a model with predetermined prices, state-contingent inflationary pressures will cause misallocations of resources whose welfare costs may exceed the benefits arising from an inflationary shock absorber (Siu, 2004), (Schmitt-Grohe, Uribe, 2002), (Angeletos, 2003). Third, certain features of financial markets may make state-contingent inflation an undesirable way to balance the budget. For example, some have argued that safe public debt serves an important comparator benchmark role. For such debt to be marketable, its return should be safe from credit risk. (For further discussion of these issues, see (Kumhof, Tanner, 2005.))

\section{A Debt Targeting (DT) Regime}

To address the potentially large and unpredictable fluctuations in debt under the TS regime, we next consider an (ad hoc) debt targeting regime (DT). Under this regime, taxes are determined by:

$$
\tau_{t}^{D T}=\gamma+r b_{t-1}^{D T}+\alpha\left[b_{t-1}^{D T}-b^{*}\right]
$$

where $b_{t-1}{ }^{T S} \equiv B_{t-1}{ }^{D T} / \hat{Y}^{P}{ }_{t \mid t-1}$ and $b^{*}$ is the (ad hoc) target debt (assumed to be equal to the initial debt level $b_{0}$ ) and $\alpha$ is the adjustment coefficient implied by the signal extraction model: the authority only responds to permanent deviations from the debt target.

This regime resembles some fiscal rules currently in place. An example would be the European Union's Stability and Growth Pact (SGP). The SGP calls for a long-run debt ceiling to output ratio in member countries not to exceed 60 percent of output (as well as a flow deficit target that is not always binding). 
The key advantage of this regime is that it helps prevent the wide swings in debt that might occur over time under a tax-smoothing regime. That is, looking $J$ periods ahead, the authority will have a better idea what the end-period debt ratio $b_{J}$ will be under the DT regime than under the TS regime.

However, this regime also has a clear drawback: it implies more volatile tax rates - fiscal adjustments that are more frequent and deeper than under TS. Such a policy inhibits countercyclical borrowing insofar as it may require adjustments during a recession. Also, spreading out the adjustment over time more gradually - setting the adjustment coefficient in (12) to some number less than $\alpha$ - would simply increase the permanent accumulation of debt.

\section{A Precautionary (PR) Fiscal Regime}

In this section, we consider a third regime that is designed to guard against future tax and debt increases. In doing so, we rephrase the government's objective function: the fiscal authority targets a primary surplus today with the aim of precluding future fiscal adjustments for all but the most unfavorable $z$-percent of macroeconomic circumstances (where $z$ is some "small" number - presumably less than 50 percent).

In recent years, policy has been increasingly cast in such terms. For example, the IMF (2003) has recently developed a "stress test" approach under which the authority aims for a primary surplus that is expected to stabilize (or reduce) the debt. Under this approach, scenarios are presented in which key variables (including growth and interest rates) are assumed to deviate from their baseline value by two standard deviations.

In a similar vein, Kopits and Barnhill (2003) suggest using a value-at-risk (VaR) methodology to fiscal sustainability. In such an approach, the government estimates both the mean and the variance of relevant fiscal variables. Likewise, Mendoza and Oviedo (2004) emphasize the role of the fiscal authority as a "tormented insurer." Under their approach, as the variability of fiscal shocks rises, the country's maximum sustainable debt ratio falls.

Such an objective function relates to recent stochastic simulations of debt sustainability - including "fan charts" - proposed by Hoffmaister et al. (2001), Garcia and Rigobon (2004), Hostland and Karam (2006), Celasun, Debrun, and Ostry (2006), and Tanner and Samake (2008). In their frameworks, substantial increases in public debt become increasingly likely over time, even when the fiscal stance remains unchanged. This must be so: the forecast variance of debt increases with horizon length. These approaches plainly reveal the probability of undesirable outcomes - essentially the upper tails of the "fan chart." Our objective function helps recast such simulations in a normative light: it summarizes the maximum fiscal adjustment that a country is willing to suffer in order to avoid further increases in debt (in probability terms, over a given horizon).

If the government aims to avoid further adjustment with a probability of less than 50 percent, it will also, on average, reduce the debt. This is because, under such a regime, the primary surplus must exceed that prescribed by the TS regime, by some factor that is linked to the variability of the tax burden. (Formally, the tax burden is all expenditures $r b+\gamma$. However, in our model, the major source of tax burden va- 
riability comes from the debt $b$, since the primary expenditure ratio $\gamma$ remains constant.)

We assume a linear relationship between the debt/output ratio and the standard deviation of the tax burden by the coefficient $\omega$. That is, the variability of the tax burden is $\omega b$. A priori, such an assumption makes sense, since the only other source of variance would be the primary expenditure ratio $\gamma-$ a variable that we have assumed that the government maintains ex ante constant. However, this assumption is also borne out by simulations (discussed below).

Thus, under a precautionary regime, tax rates are determined according to:

$$
\tau_{t}^{P R}=\gamma+(r+\kappa \omega) b_{t-1}^{P R}
$$

where $b_{t-1}^{P R} \equiv B_{t-1}^{P R} / \hat{Y}_{t \mid t-1}^{P}$. As a formal matter, the objective function underlying (13) cannot be linear quadratic. As the literature on precautionary savings (Kimball, 1990), (Carroll, Kimball, 1996), (Caballero, 1990) emphasizes, such a precautionary element like that found in (13) requires that the government's objective function also has a nonzero third moment.

At the same time, it is difficult to link regime (13) to a specific functional form in a way that is consistent with the linear, least-squares forecasting problem implied by equations (1a)-(1b). As Sargent (1987, p. 396) explains, under quadratic objective functions, linear forecasts can be derived separately from the optimization problem. This property - widely known as "certainty equivalence" - does not generalize to objective functions with higher-level moments. That is, while the first order condition implied by quadratic function (7) will include linear forecasts of future marginal tax collection costs; the first order condition implied by objective functions with a third moment will include nonlinear marginal collection costs.

Most noncertainty equivalent models are technically complex. We confine ourselves here to a special case that can motivate policy rules with a precautionary element. Thus, consider the constant absolute risk aversion (CARA)/exponential loss function:

$$
\Phi\left(\tau_{t}\right)=-1 / \phi \exp \left(-\phi \tau_{t}\right)
$$

By analogy with Caballero's (1990) work on household consumption, this functional form has an important implication: it yields an expression for the optimal tax rate that is contingent on expenditures, debt, and volatility. ${ }^{7}$ Such an analogy is straightforward if there is no signal extraction problem (the polar cases $q=\infty$ and $q=0$ in (1a)-(1b) that are equivalent to ones explicitly considered by Caballero). In other cases, such a functional form is better thought of as a heuristic device. ${ }^{8}$

Note that, so long as $\phi$ is nonzero, the function has a nonzero third derivative, which gives rise to a precautionary motive for household saving - a positive relationship between saving and the variance of the driving process. Moreover, the ratio

\footnotetext{
${ }^{7}$ This functional form is not necessary to obtain precautionary behavior, but it does yield an exact solution. Talmain (1998) provides approximations for other functional forms.

${ }^{8}$ Caballero considered several cases of a single shock to labor output, including random walk $(q=\infty$ in our model) and white noise $(q=0)$. However, the nonpolar cases of (1a)-(1b) involve two separate shocks ones that agents are unable to contemporaneously distinguish.
} 
$\Phi^{\prime \prime \prime} \mid \Phi^{\prime \prime}$ is said to be a measure of "prudence" (Kimball, 1990). ${ }^{9}$ Note next that the Euler equation for any two periods $t$ ( $\tau$ known) and $t+1$ ( $\tau$ unknown) is:

$$
\exp \left(-\phi \tau_{t}\right) / E\left[\exp \left(-\phi \tau_{t+1}\right)\right]=(1+\varphi) /(1+r)
$$

Then, following Caballero (1990), it can be shown that if output variance is normally distributed, Euler equation (15) implies that the nonstochastic component to tax rates is:

$$
\tau_{t}=\tau_{t-1}+\phi \sigma_{t}^{2} / 2
$$

where $\sigma^{2}$ is the variance of the total tax burden (discussed below). ${ }^{10}$ Thus, the case of $\phi=0$ is equivalent to the tax smoothing regime discussed in the previous section. By contrast, if $\phi<0$, fiscal policy may be said to have a precautionary element, insofar as the authority attempts to avoid future adjustments by raising today's primary surplus beyond the minimum required to keep the (expected) debt ratio constant.

Note also that substituting (16) into the budget constraint (4) and the transversality condition (5) yields a long-run (expected) relationship between tax rates, expenditure, and debt:

$$
\tau_{t}^{*}=\kappa_{t}^{*}+\gamma_{t}+r b_{t-1}
$$

where $\kappa_{t}^{*} \equiv \kappa\left(\sigma_{t}^{2}\right)^{*}=-\phi \sigma_{t}^{2} / 2$. By assumption, $\kappa_{t}^{*}$ is time-varying: the variance of the tax burden $(\gamma+r b)$ falls as the debt ratio itself falls.

The prudence parameter $-\phi$ has an alternative, common-sense interpretation, consistent with the value-at-risk approach: it summarizes the willingness to pay for a precautionary cushion. If $-\phi$ equals or exceeds some critical value $-\phi(z), 0<z<1$, the government will be willing to levy taxes today sufficient to "cover itself" with pro-

\footnotetext{
${ }^{9}$ Alternatively, the statistical term for the third moment, namely skewness, helps illustrate the nature of the preference function: the authority places an extra weight on the unattractive prospect of raising taxes.

${ }^{10}$ The following informal argument will show that, if $\phi<0$, there will be a positive relationship between volatility and the optimal tax rate. First, repeating for convenience expression (15), the Euler equation for any two periods $t$ ( $\tau$ known) and $t+1$ ( $\tau$ unknown) is:
}

$$
\exp \left(-\phi \tau_{t}\right) / E\left[\exp \left(-\phi \tau_{t+1}\right)\right]=(1+\varphi) /(1+r)
$$

In steady state $(r=\varphi)$, taking the natural logarithm of (15) yields:

$$
\ln \left\{\exp \left(-\phi \tau_{t}\right)\right\}=\ln \left\{E\left[\exp \left(-\phi \tau_{t+1}\right)\right]\right\}
$$

Following Caballero (1990), we conjecture that the future tax rate $\tau_{t+1}$ contains two components: a constant one $\left(\tau_{t+1}{ }^{*}\right)$ and a variable one $\left(v_{t+1}\right)$. Then, note that $E\left(v_{t+1}\right)=0$. The corresponding marginal loss associated with $E\left(v_{\mathrm{t}+1}\right)$ is:

$$
\phi^{\prime}(0)=\exp \left(-\phi^{*} 0\right)=1
$$

The natural logarithm of the above term is $\ln \left(\phi^{\prime}(0)\right)=\ln \left(\exp \left(-\phi^{*} 0\right)\right)=0$. By Jensen's inequality, since $E(\ln (X))<\ln (E(X)), E\left(\ln \left(\exp \left(-\phi v_{t+1}\right)\right)\right.$ must be less than zero. If Euler equation (15) is re-written as:

$$
\phi^{\prime}\left(\tau_{t}\right)=E\left(\phi^{\prime}\left(\tau_{t+1}{ }^{*}\right)\right)+E\left(\phi^{\prime}\left(v_{t+1}\right)\right)
$$

it is easily seen that the marginal losses behave according to $\phi^{\prime}\left(\tau_{t}\right)<E\left(\phi^{\prime}\left(\tau_{t+1}^{*}\right)\right)$ (since $\left.E\left(\phi^{\prime}\left(v_{t+1}\right)\right)<0\right)$. Therefore, for $\phi<0, \tau_{t+1}<\tau_{t}$. 
TABLE 1 Variance Parameters for Simulations

\begin{tabular}{|c|c|c|c|}
\hline $\begin{array}{c}\operatorname{Var}(\boldsymbol{\varepsilon}) \\
\text { (permanent) }\end{array}$ & $\begin{array}{c}\operatorname{Var}(\boldsymbol{\eta}) \\
\text { (temporary) }\end{array}$ & $\boldsymbol{q}$ & $\boldsymbol{\alpha}$ \\
\hline 6.25 & 0.00 & $\infty$ & 1.00 \\
5.47 & 0.78 & 7.00 & 0.88 \\
4.69 & 1.56 & 3.00 & 0.79 \\
3.13 & 3.13 & 1.00 & 0.62 \\
1.56 & 4.69 & 0.33 & 0.43 \\
0.78 & 5.47 & 0.14 & 0.31 \\
0.00 & 6.25 & 0.00 & 0.00 \\
\hline
\end{tabular}

bability $(1-z) .{ }^{11}$ Thus, the critical value of $-\phi(z)$ tells us the minimum "prudence" required for a government to choose to run a primary surplus sufficient to avoid further adjustment for all but the worst $z$ percent of state contingencies.

\section{Simulation Results}

This section presents simulations of regimes TS, DT, and PR for alternative parameter values. ${ }^{12}$ Repeated $J$ period histories are drawn, for both short and long horizons, $J=20$ and 100 . In all cases, 1000 simulations are computed.

Key parameters were chosen to conform broadly to emerging markets. However, alternative assumptions for variances and interest rates, not presented here, yield qualitatively similar results. In all cases, the standard deviation of total output (permanent and temporary components combined, $\operatorname{var}(\varepsilon+\eta)$ ) is assumed to be 2.5 . For each simulation, several alternative values for the signal-to-noise ratio $(q)$ are presented - see Table 1 . $^{13}$

Periods are thought of as "quarters". Output in the initial quarter is 100 , initial debt is 200 ( 50 percent of yearly output); the primary expenditure ratio $\gamma=20$ percent. The interest rate is assumed to be 2 percent (about 8 percent yearly). Thus, the mean tax rates under TS and DT $\tau_{0}=24$ percent; under perfect certainty, the debt stabilizing primary surplus is 4 percent of yearly output.

Under the precautionary regime $P R$ the initial tax rate $\tau_{0}$ is assumed to be 24.5 percent; this is $1 / 2$ percent of output greater than $\tau_{0}$ under TS/DT. This "front-loaded" adjustment keeps the debt from rising in all but the worst 15-20 percent of cases, depending on the value of $q$.

\subsection{The Behavior of Debt across Regimes}

While the debt ratio $b$ is typically most interesting for policymakers, looking at the debt level $B_{T}$ reveals some effects of the chosen fiscal policy itself - as opposed

\footnotetext{
${ }^{11}$ Thus, assuming that shocks are distributed normally, choice of $z \%$ corresponds to $k(z)$ times $\sigma(k(0.5)=$ $=1.64, k(0.1)=1.3, k(0.15)=1.04$, etc. $)$. And, $\phi=-2 / \sigma[k(z)]$.

${ }^{12}$ All simulations are performed in RATS.

${ }^{13}$ A referee correctly points out that, in the strict sense, the variance pairs in Table 1 do not keep total variance constant. To see this, suppose (hypothetically) that $Y_{t}^{P}=\rho Y^{P}{ }_{t-1}+\eta_{t}$, where $\rho<1$. Thus, $\operatorname{var}\left(Y^{P}\right)=$ $=\operatorname{var}(\eta) /\left(1-\rho^{2}\right)$ : the variance of $Y^{P}$ does not move one-to-one with the variance of $\eta$. As a remedy, we performed two supplemental sets of simulations. One set of simulations considers alternative values of $\operatorname{var}(\eta)$ for a fixed value $\operatorname{var}(\varepsilon)=3.13$. The other set considers alternative values of $\operatorname{var}(\varepsilon)$ for a fixed value of $\operatorname{var}(\eta)=3.13$. Results, available from the authors, largely confirm the analysis in the body of the paper.
} 
TABLE 2 Selected Statistics, Simulated Debt Ratios $\left(b_{J}\right)$, and Levels $\left(B_{J}\right)$ after 20 Periods $(\mathrm{J}=20)$; (SD = standard deviation)

\begin{tabular}{|c|c|c|c|c|c|c|c|c|c|}
\hline & \multicolumn{4}{|c|}{ Debt Ratio $\left(b_{20}\right)$} & \multicolumn{4}{|c|}{ Debt Level $\left(B_{20}\right)$} \\
\hline & & \multirow{2}{*}{ Mean } & \multirow{2}{*}{ SD } & \multicolumn{2}{|c|}{ Percentiles } & \multirow{2}{*}{ Mean } & \multirow{2}{*}{ SD } & \multicolumn{2}{|c|}{ Percentiles } \\
\hline & & & & $75^{\text {th }}$ & $90^{\text {th }}$ & & & $75^{\text {th }}$ & $90^{\text {th }}$ \\
\hline \multirow[t]{3}{*}{$q \rightarrow \infty, \alpha=1$} & TS & 0.51 & 0.07 & 0.55 & 0.59 & 200.0 & 2.7 & 201.9 & 203.5 \\
\hline & DT & 0.50 & 0.00 & 0.50 & 0.50 & 200.0 & 22.6 & 215.4 & 228.9 \\
\hline & TP & 0.48 & 0.06 & 0.52 & 0.57 & 190.3 & 2.7 & 192.1 & 193.7 \\
\hline \multirow[t]{3}{*}{$q=8, \alpha=0.88$} & TS & 0.50 & 0.06 & 0.54 & 0.59 & 199.9 & 2.8 & 201.7 & 203.5 \\
\hline & DT & 0.50 & 0.00 & 0.50 & 0.51 & 200.7 & 20.7 & 215.3 & 227.0 \\
\hline & TP & 0.48 & 0.06 & 0.51 & 0.56 & 190.2 & 2.8 & 192.0 & 193.8 \\
\hline \multirow[t]{3}{*}{$q=3, \alpha=0.79$} & TS & 0.51 & 0.06 & 0.54 & 0.59 & 200.0 & 2.9 & 202.0 & 204.0 \\
\hline & DT & 0.50 & 0.01 & 0.50 & 0.51 & 199.8 & 18.9 & 212.4 & 223.7 \\
\hline & TP & 0.48 & 0.06 & 0.51 & 0.56 & 190.3 & 2.9 & 192.3 & 194.3 \\
\hline \multirow[t]{3}{*}{$q=1, \alpha=0.62$} & TS & 0.50 & 0.05 & 0.53 & 0.57 & 200.0 & 3.0 & 202.0 & 204.0 \\
\hline & DT & 0.50 & 0.01 & 0.51 & 0.51 & 199.8 & 14.9 & 210.0 & 218.4 \\
\hline & TP & 0.48 & 0.05 & 0.51 & 0.54 & 190.3 & 3.0 & 192.3 & 194.2 \\
\hline \multirow[t]{3}{*}{$q=0.33, \alpha=0.43$} & TS & 0.50 & 0.04 & 0.53 & 0.55 & 200.0 & 3.0 & 202.0 & 204.1 \\
\hline & DT & 0.50 & 0.01 & 0.51 & 0.52 & 200.0 & 9.8 & 207.1 & 212.5 \\
\hline & TP & 0.48 & 0.04 & 0.50 & 0.53 & 190.3 & 2.9 & 192.3 & 194.3 \\
\hline \multirow[t]{3}{*}{$q=0.14, \alpha=0.31$} & TS & 0.50 & 0.03 & 0.52 & 0.54 & 199.9 & 2.9 & 201.9 & 203.6 \\
\hline & DT & 0.50 & 0.01 & 0.51 & 0.52 & 200.1 & 6.4 & 204.7 & 208.3 \\
\hline & TP & 0.48 & 0.03 & 0.49 & 0.51 & 190.2 & 2.9 & 192.2 & 193.9 \\
\hline \multirow[t]{3}{*}{$q=0, \alpha=0$} & TS & 0.50 & 0.02 & 0.51 & 0.52 & 199.9 & 2.7 & 201.6 & 203.3 \\
\hline & DT & 0.50 & 0.02 & 0.51 & 0.52 & 199.9 & 2.7 & 201.6 & 203.3 \\
\hline & TP & 0.48 & 0.02 & 0.49 & 0.50 & 190.2 & 2.6 & 191.9 & 193.5 \\
\hline
\end{tabular}

to effects due to changes in the scale variable $Y$. Thus, Tables 2 and 3 summarize selected properties of both the debt ratio $(b)$ and the debt level $(B)$ at the end of $J$ periods $(J=20,100)$, for 1000 simulations of regimes TS, DS, and PR. The table reports the mean, the standard deviation, and values for the $75^{\text {th }}$ and $90^{\text {th }}$ percentiles. These latter statistics are consistent with value at risk (VaR) approaches (for example (Kopits, Barnhill, 2003)): they tell us that the debt (ratio or level) exceeds the critical value in 25 or 10 percent of the simulations.

Results reveal that, under a tax smoothing (TS) regime, for the cases where permanent shocks are more important (higher $q$ ) it is more difficult to stabilize the debt ratio. For both horizons $J=20$ and $J=100$, the increase in the mean debt ratio (previously discussed) is evident. As $q$ increases, so does the increase in mean debt $b_{J}$. And, the standard deviation of the terminal debt ratio $b_{J}$ increases monotonically with $q$. Likewise, as $q$ rises so do the $75^{\text {th }}$ and $90^{\text {th }}$ percentile statistics.

Hence, for more permanent shocks (higher $q$ ), debt increases are more severe in the worst 25 and 20 percent of cases. As Table 2 shows, for a twenty-period horizon $(J=20$, about five years), if all shocks are permanent (infinite $q)$, the terminal value of the debt ratio $b_{20}$ equals or exceeds 55 percent of output in 25 percent $\left(75^{\text {th }}\right.$ percentile statistic) and 59 percent of output in 10 percent $\left(90^{\text {th }}\right.$ percentile statistic). 
TABLE 3 Selected Statistics, Simulated Debt Ratios $\left(b_{J}\right)$, and Levels $\left(B_{J}\right)$ after 100 Periods $(J=100)(S D=$ standard deviation $)$

\begin{tabular}{|c|c|c|c|c|c|c|c|c|c|}
\hline & \multicolumn{4}{|c|}{ Debt Ratio $\left(b_{100}\right)$} & \multicolumn{4}{|c|}{ Debt Level $\left(B_{100}\right)$} \\
\hline & & \multirow{2}{*}{ Mean } & \multirow{2}{*}{ SD } & \multicolumn{2}{|c|}{ Percentiles } & \multirow{2}{*}{ Mean } & \multirow{2}{*}{ SD } & \multicolumn{2}{|c|}{ Percentiles } \\
\hline & & & & $75^{\text {th }}$ & $90^{\text {th }}$ & & & $75^{\text {th }}$ & $90^{\text {th }}$ \\
\hline \multirow[t]{3}{*}{$q \rightarrow \infty, \alpha=1$} & TS & 0.55 & 0.24 & 0.62 & 0.76 & 200.0 & 6.0 & 204.2 & 207.7 \\
\hline & DT & 0.50 & 0.00 & 0.50 & 0.50 & 200.0 & 50.0 & 234.6 & 264.9 \\
\hline & TP & 0.43 & 0.19 & 0.49 & 0.60 & 155.9 & 5.4 & 159.7 & 162.6 \\
\hline \multirow[t]{3}{*}{$q=8, \alpha=0.88$} & TS & 0.55 & 0.20 & 0.62 & 0.77 & 200.4 & 6.5 & 204.2 & 207.7 \\
\hline & DT & 0.50 & 0.01 & 0.50 & 0.51 & 197.2 & 47.2 & 229.8 & 258.3 \\
\hline & TP & 0.43 & 0.16 & 0.49 & 0.61 & 156.2 & 5.7 & 160.0 & 163.8 \\
\hline \multirow[t]{3}{*}{$q=3, \alpha=0.79$} & TS & 0.52 & 0.14 & 0.58 & 0.70 & 199.4 & 6.5 & 203.7 & 207.7 \\
\hline & DT & 0.50 & 0.01 & 0.50 & 0.51 & 203.9 & 43.0 & 233.2 & 260.5 \\
\hline & TP & 0.40 & 0.11 & 0.46 & 0.54 & 155.4 & 5.8 & 159.1 & 162.8 \\
\hline \multirow[t]{3}{*}{$q=1, \alpha=0.62$} & TS & 0.52 & 0.12 & 0.58 & 0.66 & 199.8 & 6.7 & 204.6 & 208.2 \\
\hline & DT & 0.50 & 0.01 & 0.51 & 0.52 & 201.2 & 34.1 & 224.6 & 245.0 \\
\hline & TP & 0.40 & 0.09 & 0.45 & 0.52 & 155.6 & 5.9 & 160.0 & 163.1 \\
\hline \multirow[t]{3}{*}{$q=0.33, \alpha=0.43$} & TS & 0.51 & 0.09 & 0.56 & 0.62 & 199.8 & 6.8 & 204.3 & 208.3 \\
\hline & DT & 0.50 & 0.01 & 0.51 & 0.52 & 200.8 & 24.3 & 216.7 & 231.9 \\
\hline & TP & 0.40 & 0.07 & 0.44 & 0.48 & 155.7 & 6.0 & 159.7 & 163.3 \\
\hline \multirow[t]{3}{*}{$q=0.14, \alpha=0.31$} & TS & 0.51 & 0.07 & 0.55 & 0.59 & 200.3 & 6.8 & 204.8 & 209.0 \\
\hline & DT & 0.50 & 0.02 & 0.51 & 0.52 & 199.3 & 17.3 & 211.4 & 221.1 \\
\hline & TP & 0.40 & 0.05 & 0.43 & 0.47 & 156.1 & 6.0 & 160.1 & 163.8 \\
\hline \multirow[t]{3}{*}{$q=0, \alpha=0$} & TS & 0.50 & 0.02 & 0.51 & 0.53 & 200.3 & 6.1 & 204.3 & 207.6 \\
\hline & DT & 0.50 & 0.02 & 0.51 & 0.53 & 200.3 & 6.1 & 204.3 & 207.6 \\
\hline & TP & 0.39 & 0.02 & 0.40 & 0.41 & 156.1 & 5.4 & 159.6 & 162.6 \\
\hline
\end{tabular}

Likewise, as Table 3 shows, the corresponding statistic for a 100 period horizon $\left(J=100\right.$, about 25 years), the terminal value of the debt ratio $b_{100}$ equals or exceeds 62 percent of output in 25 percent of cases ( $75^{\text {th }}$ percentile); $b_{100}$ equals or exceeds 76 percent of output in 10 percent of cases $\left(90^{\text {th }}\right.$ percentile.)

Interestingly, the unscaled debt levels $B_{J}$ reveal a nonmonotonic relationship between $q$ and the volatility of $B_{J}$. The relationship has an "inverse $U$ " shape: the standard deviation of end-period debt $B_{J}$ and its $75^{\text {th }}$ and $90^{\text {th }}$ percentiles are highest at intermediate values of $q$ (specifically $q \approx 0.33$ ) - cases with both temporary and permanent shocks. This result reflects the fact that (as discussed previously) persistent shocks to debt take place in a TS regime precisely because agents do not initially know whether a given shock is temporary or permanent.

Simulations also reveal that the debt targeting (DT) regime achieves its goal. In all cases, the standard deviations of debt ratios $b_{J}$ (but not levels $B_{J}$ ) fall dramatically, as do the $75^{\text {th }}$ and $90^{\text {th }}$ percentiles. (As previously mentioned, for $q=0$, TS and DT are equivalent.)

And, the precautionary regime (PR) reduces the mean debt level and ratios relative to both TS and DT as expected. As Table 2 shows, after 20 periods, the mean debt ratio $b_{20}$ drops from its initial value of 50 percent of output to about 48 percent. 
Moreover, as Table 3 shows, after one hundred periods, the mean debt ratio $b_{100}$ drops further still to about 43 percent.

And, PR provides less debt volatility relative to TS (but not DT).

However, for cases where permanent shocks are more important (higher $q$ ), the precautionary regime PR implies a relatively larger "cushion." Hence, for the 20-period simulation (Table 2), under the PR regime, the $75^{\text {th }}$ and $90^{\text {th }}$ percentiles for $b_{J}$ are 52 percent and 57 percent of output respectively (as opposed to 55 percent and 59 percent of output under the TS regime). Likewise, for the 100-period simulation (Table 3), under the PR regime, the $75^{\text {th }}$ and $90^{\text {th }}$ percentiles for $b_{y}$ are 49 percent and 60 percent respectively (as opposed to 62 percent and 76 percent under the TS regime).

\subsection{The Behavior of Tax Rates across Regimes}

As discussed above, tax rates, rather than debt ratios, directly impact the citizens of a country. Collection cost functions (7) and (14) are meant to reflect the distortionary impacts of taxes. Thus, we also examine the behavior of the tax rate $\tau$. How do tax rates behave under the alternative regimes? Does the debt targeting (DT) regime represent an attractive policy option? Accordingly, simulated data on tax rates are presented both graphically and in tables.

As mentioned previously, the initial tax rate $\tau_{0}$ is about 24 percent under TS and DT but 24.5 percent under PR. Note that under PR (and unlike TS or DT) taxes fall over time. As Table 4 shows, after 20 periods, under regime PR, the tax rate $\tau_{J}$ falls to about 24.3 percent; after 100 periods, $\tau_{100}$ falls slightly below the tax rates implied by TS or DT.

Average simulated tax rates for regimes TS, DT, and PR (taken over 1000 draws) are graphed in Figures $1 a-1 g$ (at the end of this section) for alternative values of $q$. Casual observation reveals that for high values of $q$ (for example $q=\infty, F i$ gure $1 a$ ) the TS regime yields a tax rate that rises gradually over time. Under the DT regime, taxes are more volatile but do not appear to drift upwards. And, under the PR regime, tax rates are initially higher than under DT or PR but fall over time. However, as $q$ falls, the upward drift under TS becomes less pronounced; for the case of $q=0$ (Figure $1 g$ ), the tax rate under TS appears to be roughly constant over time. Also, as $q$ falls, the behavior of DT gradually becomes more similar to that of TS; for the case of $q=0$ (Figure $1 g$ ), TS and DT are identical.

To supplement the graphs, Tables 4 and 5 present the mean, standard deviation, $75^{\text {th }}$, and $90^{\text {th }}$ percentiles of within-period and end-period tax rates $\left(\tau_{j}\right.$, and $\tau_{J}$ respectively) for 20 and 100 period horizons, respectively.

According to these tables, for cases where permanent shocks are more important (high $q$ ), the TS regime is a relatively less effective policy for stabilizing tax rates. Instead, tax rate variability and $q$ are positively related. Thus, at the end of a 20-year horizon $(J=20)$, if all shocks are permanent $(q=\infty)$, there is a 25 percent chance $\left(75^{\text {th }}\right.$ percentile statistic) that the tax rate $\tau_{20}$ will be at least 24.4 percent; for the worst 10 percent of cases $\left(90^{\text {th }}\right.$ percentile statistic), the tax rate $\tau_{20}$ will be at least 24.7 percent. Likewise, after 100 periods $(J=100)$, if all shocks are permanent $(q=$ $=\infty)$, there is a 25 percent chance $\left(75^{\text {th }}\right.$ percentile statistic) that the tax rate $\tau_{100}$ will be 
TABLE 4 Selected Statistics, Simulated Tax Rates, Within Period $\left(\tau_{J}, j=1\right.$ to $\left.J\right)$, and End-Period $\left(T_{J}\right), 20$ Periods $(J=20)(S D=$ standard deviation $)$

\begin{tabular}{|c|c|c|c|c|c|c|c|c|c|}
\hline & \multicolumn{4}{|c|}{$\begin{array}{c}\text { Within-Period Tax Rate } \\
\tau_{j}, j=1 \text { to } 20\end{array}$} & \multicolumn{4}{|c|}{ End-Period Tax Rate $\tau_{20}$} \\
\hline & & \multirow{2}{*}{ Mean } & \multirow{2}{*}{ SD } & \multicolumn{2}{|c|}{ Percentiles } & \multirow{2}{*}{ Mean } & \multirow{2}{*}{ SD } & \multicolumn{2}{|c|}{ Percentiles } \\
\hline & & & & $75^{\text {th }}$ & $90^{\text {th }}$ & & & $75^{\text {th }}$ & $90^{\text {th }}$ \\
\hline \multirow[t]{3}{*}{$q \rightarrow \infty, \alpha=1$} & TS & 0.240 & 0.002 & 0.242 & 0.243 & 0.241 & 0.005 & 0.244 & 0.247 \\
\hline & DT & 0.241 & 0.050 & 0.273 & 0.300 & 0.243 & 0.052 & 0.276 & 0.307 \\
\hline & TP & 0.244 & 0.002 & 0.246 & 0.247 & 0.244 & 0.006 & 0.247 & 0.251 \\
\hline \multirow[t]{3}{*}{$q=8, \alpha=0.88$} & TS & 0.240 & 0.002 & 0.241 & 0.242 & 0.240 & 0.005 & 0.243 & 0.247 \\
\hline & DT & 0.241 & 0.041 & 0.267 & 0.290 & 0.242 & 0.044 & 0.270 & 0.300 \\
\hline & TP & 0.244 & 0.002 & 0.246 & 0.247 & 0.243 & 0.005 & 0.246 & 0.250 \\
\hline \multirow[t]{3}{*}{$q=3, \alpha=0.79$} & TS & 0.240 & 0.002 & 0.241 & 0.242 & 0.240 & 0.005 & 0.243 & 0.247 \\
\hline & DT & 0.241 & 0.035 & 0.264 & 0.283 & 0.243 & 0.037 & 0.267 & 0.291 \\
\hline & TP & 0.244 & 0.002 & 0.246 & 0.247 & 0.243 & 0.005 & 0.246 & 0.250 \\
\hline \multirow[t]{3}{*}{$q=1, \alpha=0.62$} & TS & 0.240 & 0.001 & 0.241 & 0.242 & 0.240 & 0.004 & 0.243 & 0.245 \\
\hline & DT & 0.241 & 0.024 & 0.256 & 0.270 & 0.239 & 0.025 & 0.256 & 0.271 \\
\hline & TP & 0.244 & 0.002 & 0.245 & 0.246 & 0.243 & 0.004 & 0.246 & 0.249 \\
\hline \multirow[t]{3}{*}{$q=0.33, \alpha=0.43$} & TS & 0.240 & 0.001 & 0.241 & 0.241 & 0.240 & 0.003 & 0.242 & 0.244 \\
\hline & DT & 0.241 & 0.014 & 0.249 & 0.258 & 0.241 & 0.016 & 0.251 & 0.263 \\
\hline & TP & 0.244 & 0.001 & 0.245 & 0.246 & 0.243 & 0.003 & 0.245 & 0.247 \\
\hline \multirow[t]{3}{*}{$q=0.14, \alpha=0.31$} & TS & 0.240 & 0.001 & 0.241 & 0.241 & 0.240 & 0.002 & 0.241 & 0.243 \\
\hline & DT & 0.240 & 0.008 & 0.246 & 0.250 & 0.240 & 0.011 & 0.247 & 0.254 \\
\hline & TP & 0.244 & 0.001 & 0.245 & 0.245 & 0.243 & 0.002 & 0.244 & 0.246 \\
\hline \multirow[t]{3}{*}{$q=0, \alpha=0$} & TS & 0.240 & 0.000 & 0.240 & 0.240 & 0.240 & 0.001 & 0.240 & 0.241 \\
\hline & DT & 0.240 & 0.000 & 0.240 & 0.240 & 0.240 & 0.001 & 0.240 & 0.241 \\
\hline & TP & 0.244 & 0.001 & 0.244 & 0.245 & 0.243 & 0.001 & 0.243 & 0.244 \\
\hline
\end{tabular}

at least 24.9 percent; for the worst 10 percent of cases $\left(90^{\text {th }}\right.$ percentile statistic), tax rates $\tau_{100}$ will be at least 26.1 percent.

Tables 4 and 5 thus confirm an unattractive aspect of a debt targeting DT regime: taxes are, by definition, made more volatile - perhaps unacceptably so. For $q=\infty$, under a DT regime, the standard deviations for end-period taxes $\tau_{20}$ and $\tau_{100}$ are substantially higher than under a TS regime. At the end of a 20-period horizon $(J=20)$, if all shocks are permanent $(q=\infty)$, there is a 25 percent chance $\left(75^{\text {th }}\right.$ percentile statistic) that the tax rate $\tau_{20}$ will be at least 27.6 percent; for the worst 10 percent of cases $\left(90^{\text {th }}\right.$ percentile statistic), the tax rate $\tau_{20}$ will be at least 30.0 percent. A 100 -period horizon $(J=100)$ yields similar results. Thus, a DT regime does stabilize the debt, but with substantially more tax rate variability.

By contrast, under the precautionary (PR) regime, simulations reveal that its initially higher tax rates yield some advantages. First, over the short term $(J=20)$, these advantages are more evident for higher values of $q$. For example, if all shocks are permanent $(q=\infty)$, during periods $t=1$ through $J$, the standard deviations of tax rates under TS and PR are about the same (0.002) - and substantially lower than under DT (0.05). Since the mean tax rate under PR is higher than under TS, so too are the $75^{\text {th }}$ and $90^{\text {th }}$ percentile statistics. Thus, the PR regime might be thought of as 
TABLE 5 Selected Statistic, Simulated Tax Rates, Within Period $\left(\tau_{j}, j=1\right.$ to $\left.J\right)$, and End-Period $\left(T_{J}\right), 100$ Periods $(J=100)$ (SD=standard deviation)

\begin{tabular}{|c|c|c|c|c|c|c|c|c|c|}
\hline & \multicolumn{4}{|c|}{$\begin{array}{c}\text { Within-Period Tax Rate } \\
\boldsymbol{T}_{j}, j=1 \text { to } 20\end{array}$} & \multicolumn{4}{|c|}{ End-Period Tax Rate $\tau_{20}$} \\
\hline & & \multirow{2}{*}{ Mean } & \multirow{2}{*}{ SD } & \multicolumn{2}{|c|}{ Percentiles } & \multirow{2}{*}{ Mean } & \multirow{2}{*}{ SD } & \multicolumn{2}{|c|}{ Percentiles } \\
\hline & & & & $75^{\text {th }}$ & $90^{\text {th }}$ & & & $75^{\text {th }}$ & $90^{\text {th }}$ \\
\hline \multirow[t]{3}{*}{$q \rightarrow \infty, \alpha=1$} & TS & 0.240 & 0.002 & 0.242 & 0.243 & 0.241 & 0.005 & 0.244 & 0.247 \\
\hline & DT & 0.241 & 0.050 & 0.273 & 0.300 & 0.243 & 0.052 & 0.276 & 0.307 \\
\hline & TP & 0.244 & 0.002 & 0.246 & 0.247 & 0.244 & 0.006 & 0.247 & 0.251 \\
\hline \multirow[t]{3}{*}{$q=8, \alpha=0.88$} & TS & 0.240 & 0.002 & 0.241 & 0.242 & 0.240 & 0.005 & 0.243 & 0.247 \\
\hline & DT & 0.241 & 0.041 & 0.267 & 0.290 & 0.242 & 0.044 & 0.270 & 0.300 \\
\hline & TP & 0.244 & 0.002 & 0.246 & 0.247 & 0.243 & 0.005 & 0.246 & 0.250 \\
\hline \multirow[t]{3}{*}{$q=3, \alpha=0.79$} & TS & 0.240 & 0.002 & 0.241 & 0.242 & 0.240 & 0.005 & 0.243 & 0.247 \\
\hline & DT & 0.241 & 0.035 & 0.264 & 0.283 & 0.243 & 0.037 & 0.267 & 0.291 \\
\hline & TP & 0.244 & 0.002 & 0.246 & 0.247 & 0.243 & 0.005 & 0.246 & 0.250 \\
\hline \multirow[t]{3}{*}{$q=1, \alpha=0.62$} & TS & 0.240 & 0.001 & 0.241 & 0.242 & 0.240 & 0.004 & 0.243 & 0.245 \\
\hline & DT & 0.241 & 0.024 & 0.256 & 0.270 & 0.239 & 0.025 & 0.256 & 0.271 \\
\hline & TP & 0.244 & 0.002 & 0.245 & 0.246 & 0.243 & 0.004 & 0.246 & 0.249 \\
\hline \multirow[t]{3}{*}{$q=0.33, \alpha=0.43$} & TS & 0.240 & 0.001 & 0.241 & 0.241 & 0.240 & 0.003 & 0.242 & 0.244 \\
\hline & DT & 0.241 & 0.014 & 0.249 & 0.258 & 0.241 & 0.016 & 0.251 & 0.263 \\
\hline & TP & 0.244 & 0.001 & 0.245 & 0.246 & 0.243 & 0.003 & 0.245 & 0.247 \\
\hline \multirow[t]{3}{*}{$q=0.14, \alpha=0.31$} & TS & 0.240 & 0.001 & 0.241 & 0.241 & 0.240 & 0.002 & 0.241 & 0.243 \\
\hline & DT & 0.240 & 0.008 & 0.246 & 0.250 & 0.240 & 0.011 & 0.247 & 0.254 \\
\hline & TP & 0.244 & 0.001 & 0.245 & 0.245 & 0.243 & 0.002 & 0.244 & 0.246 \\
\hline \multirow[t]{3}{*}{$q=0, \alpha=0$} & TS & 0.240 & 0.000 & 0.240 & 0.240 & 0.240 & 0.001 & 0.240 & 0.241 \\
\hline & DT & 0.240 & 0.000 & 0.240 & 0.240 & 0.240 & 0.001 & 0.240 & 0.241 \\
\hline & TP & 0.244 & 0.001 & 0.244 & 0.245 & 0.243 & 0.001 & 0.243 & 0.244 \\
\hline
\end{tabular}

a compromise between the TS and DT regimes: it helps attenuate debt volatility while avoiding additional tax rate volatility.

Second, if the authority keeps with a PR regime, both the mean and the variability of tax rates will fall. For a 100-period horizon $(J=100)$, the within period mean tax rate for PR is about the same or slightly less than under TS/DT; for cases in which the permanent shock is important $(q \geq 8)$, the standard deviation, the $75^{\text {th }}$, and the $90^{\text {th }}$ percentile statistics are about the same under PR and TS. Thus, as before, PR appears to be even more appealing relative to TS when the shocks are mainly permanent: it is more urgent for policymakers to insure against permanent adverse shocks than temporary adverse shocks.

Finally, the simulations reveal the benefits of debt reduction over the long term - for any value of $q$. At the end of a 100-period horizon $(J=100)$ the mean end-period tax rate $\tau_{J}$ under $P R$ is less than under TS/DT; as well, the standard deviation, $75^{\text {th }}$, and $90^{\text {th }}$ percentile statistics are all less under PR than either TS or DT for all values of $q$. 
FIGURES 1a-g Simulated Tax Rates, Regimes TS, DT, and PR
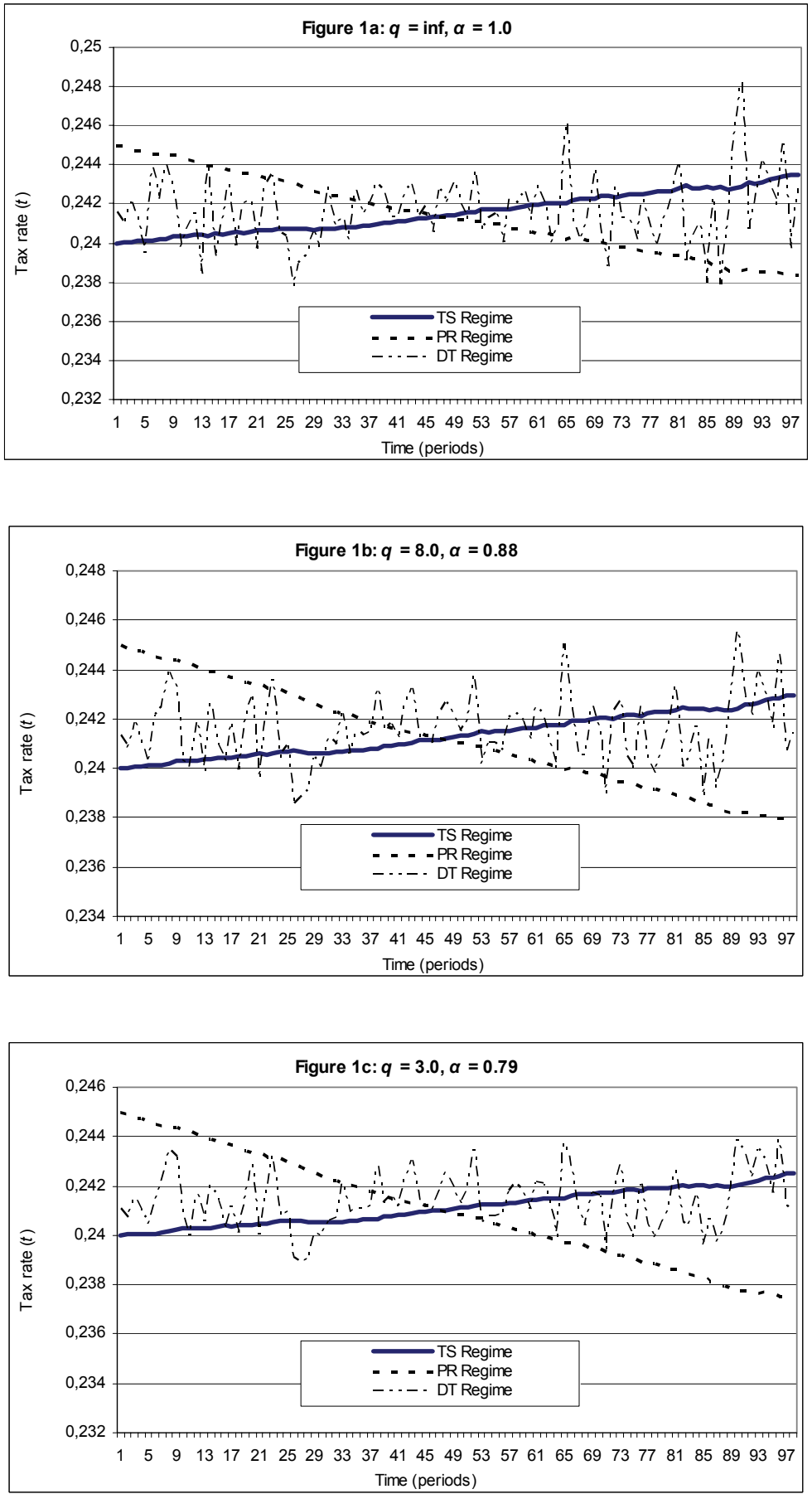

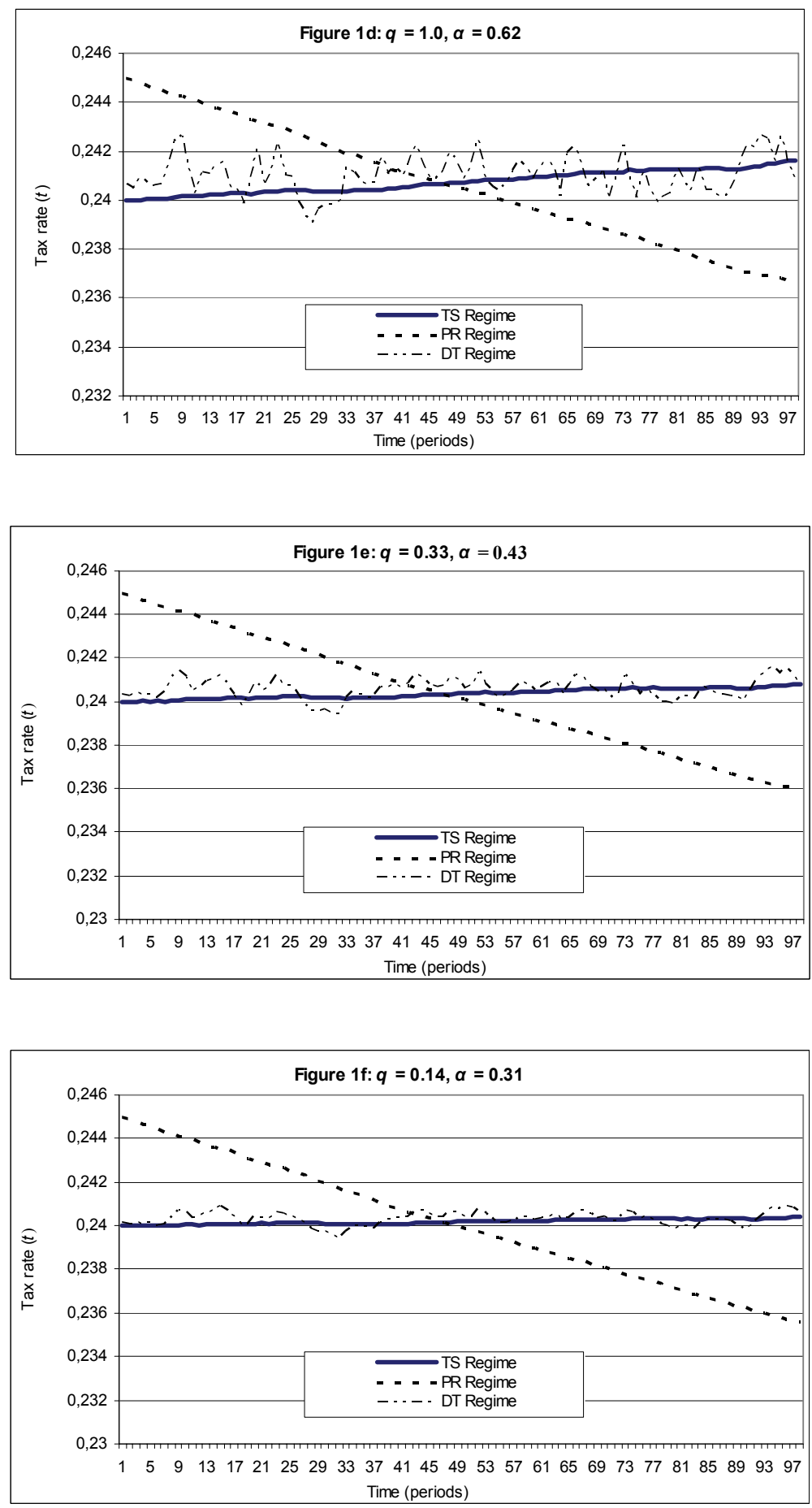


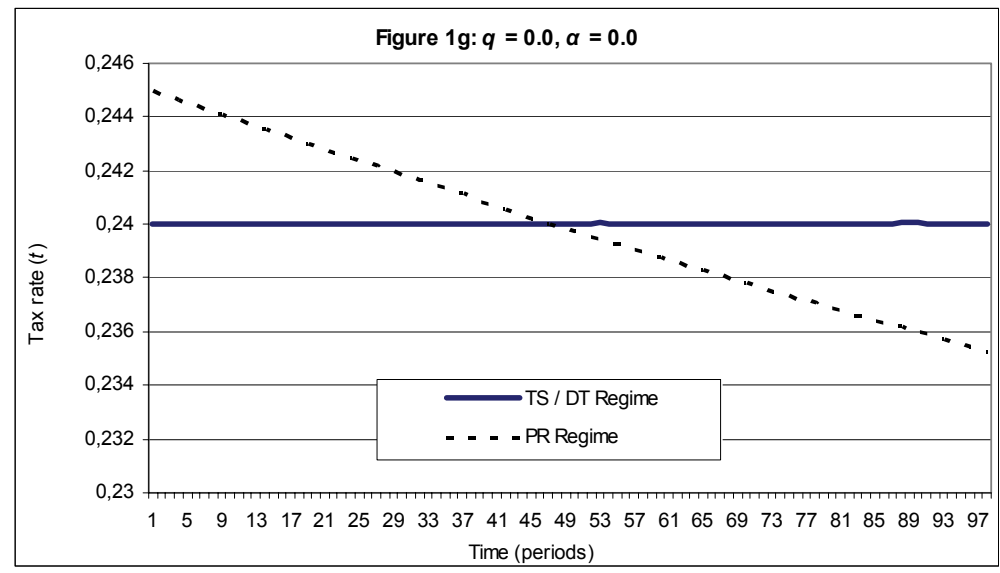

\section{Conclusions}

Tax smoothing is a canonical framework for well-intentioned fiscal policy. Under certainty, tax smoothing implies a constant debt-to-output ratio. Accordingly, such a policy does not favor the present over the future - or vice versa.

However, policymakers typically face uncertainty and they are often unsure about the true value of permanent output. Our analysis has illustrated the ways that tax smoothing can be perilous in such an environment: both debt levels and tax rates are difficult to stabilize and may drift upwards.

One practical remedy would be to target the debt. However, our simulations confirmed the undesirable nature of such a policy: it increases tax rate volatility over time and may inhibit countercyclical borrowing.

As an alternative we consider a precautionary regime. Unlike tax smoothing, which links the primary surplus to the debt ratio, a precautionary regime also links the optimal primary surplus to the volatility of the debt ratio.

Over time, a precautionary regime will reduce the debt. Plans to reduce government debt are not novel. However, the choice of any particular debt target is arbitrary and may be difficult to defend. In this sense, the credibility of government policy may be bolstered by an explicitly articulated objective function. Accordingly, under a precautionary regime, the objective is to guard against future tax and debt increases for all but the worst macroeconomic circumstances. By contrast, tax smoothing provides no such safeguard. In this sense, the ultimate goal of this paper is to foster good, clear, and understandable fiscal policies - echoing Lucas (1976) and Kydland and Prescott (1977).

In this spirit, Tanner and Samake (2008) incorporate an objective function similar to the one considered in this paper into a stochastic simulation of debt outcomes in three emerging market economies, namely Brazil, Mexico, and Turkey. 


\section{REFERENCES}

Aiyagari SR, Marcet A, Sargent TJ, Seppälä J (2002): Optimal Taxation without State-Contingent Debt. Journal of Political Economy, 110(6-December):1220-54.

Angeletos GM (2003): Comments on Benigno and Woodford's Optimal Monetary and Fiscal Policy. In: Gertler M, Rogoff K (Eds.): NBER Macroeconomics Annual 2003 (Cambridge, MA, National Bureau of Economic Research).

Barro RJ (1979): On the Determination of the Public Debt. Journal of Political Economy, 87(5-(Part 1, October):940-71.

Bayoumi T, Eichengreen B (1995): Restraining Yourself: The Implications of Fiscal Rules for Economic Stabilization. International Monetary Fund Staff Papers, 42(1-March):32-48.

Benigno P, Woodford M (2003): Optimal Monetary and Fiscal Policy: A Linear Quadratic Approach. In: Gertler M, Rogoff K (Eds.): NBER Macroeconomics Annual 2003 (Cambridge, MA, National Bureau of Economic Research).

Blanchard Ojet al. (1990): The Sustainability of Fiscal Policy: New Answers to an Old Question. OECD Economic Studies, 15(Autumn):7-34.

Burnside C (2005): Some Tools for Fiscal Sustainability Analysis. In: Burnside C (Ed.): Fiscal Sustainability in Theory and Practice. Washington D.C, World Bank.

Caballero R (1990): Consumption Puzzles and Precautionary Savings. Journal of Monetary Economics, 25:113-16.

Carroll ChD, Kimball MS (1996): On the Concavity of the Consumption Function. Econometrica, 64(4-July):981-992.

Celasun O, Debrun X, Ostry J (2006): Primary Surplus Behavior and Risks to Fiscal Sustainability in Emerging Market Countries: A 'Fan-Chart' Approach. IMF Staff Papers, 53(3):401-25

Chalk N, Hemming R (2000): Assessing Fiscal Sustainability in Theory and Practice. IMF Working Paper, no. 00/81.

Chari V, Christiano LJ, Kehoe PJ (1994): Optimal Fiscal Policy in a Business Cycle Model. Journal of Political Economy, 102(4):617-52.

Cochrane J (1998): A Frictionless model of U.S. Inflation. In: Bernanke BS, Rotemberg JJ (Eds.): NBER Macroeconomics Annual 1998 (Cambridge, MA, MIT Press):323-384.

Croce E, Juan-Ramón VH (2003): Assessing Fiscal Sustainability: A Cross-Country Analysis. Working Paper in process. (Washington, IMF).

Deaton A (1992): Understanding Consumption. Oxford, Clarendon Press.

Dréze J, Modigliani F (1972): Consumption Decisions Under Uncertainty. Journal of Economic Theory, 5:308-335.

Fisher LA, Kingston GH (2005): Joint Implications of Consumption and Tax Smoothing. Journal of Money, Credit, and Banking, 37(6-Dec): 1101-19.

Garcia M, Rigobon R (2004): A Risk Management Approach to Emerging Market's Sovereign Debt Sustainability with an Application to Brazilian Data. NBER Working Paper, no. 10336 (Cambridge, MA).

Hall GJ, Krieger S (2000): The Tax Smoothing Implications of the Federal Debt Paydown. Brookings Papers on Economic Activity, (2):253-84.

Harvey AC, (1989): Forecasting, Structural Time Series Models and the Kalman Filter. Cambridge, MA, Cambridge University Press.

Hoffmaister AW, Rojas M, Saenz M, Segura M, Tenorio E (2001): Solvency of the Overall Public Sector: A preliminary empirical study for Costa Rica. Central Bank of Costa Rica, Economics Division, Research Note, no. 04-01. 
Hostland D, Karam P (2006): Assessing Debt Sustainability in Emerging Markets using Stochastic Simulation Methods. IMF Working Paper, 06/268.

International Monetary Fund (2003a): Evaluation Report, Fiscal Adjustment in IMF-Supported Programs, Independent Evaluation Office.

available at: http://www.imf.org/external/np/ieo/2003/fis/index.htm

International Monetary Fund (2003b): Sustainability Assessments - Review of Application and Methodological Refinements.

available at: http://www.imf.org /external/np/pdr/sustain/2003/061003.pdf

Juhn G, Loungani P (2002): Further Cross-Country Evidence on the Accuracy of the Private Sector's Output Forecasts. IMF Staff Papers, 49(1):49-64.

Kimball M (1990): Precautionary Savings in the Small and in the Large. Econometrica, 58(1):53-74.

Kingston G (1991): Should Marginal Tax Rates Be Equalized Through Time? Quarterly Journal of Economics, 106(3-August):911-24.

Kopits G, Barnhill TF (2003): Assessing Fiscal Sustainability Under Uncertainty. IMF Working Paper, no. 03/79.

Kumhof M, Tanner E (2005): Government Debt: A Key Role in Financial Intermediation. IMF Working Paper, no. 05/57.

Kydland F, Prescott E (1977): Rules Rather than Discretion: The Inconsistency of Optimal Plans. Journal of Political Economy, 85(3-June):473-91.

Lloyd-Ellis H, Zhan Sh, Zhu X (2005): Tax Smoothing with Stochastic Interest Rates: A Reassessment of Clinton's Fiscal Legacy. Journal of Money, Credit, and Banking, 37(4-Aug): 699-724.

Lucas RE jr. (1976): Econometric Policy Evaluation: A Critique. In: Brunner K, Meltzer AH (Eds.): The Phillips Curve and Labor Markets. Amsterdam, North-Holland.

Lucas RE jr., Stokey N (1983): Optimal Fiscal and Monetary Policy in an Economy without Capital. Journal of Monetary Economics, 12(July):55-93.

McCallum BT (2000): The Present and Future of Monetary Policy Rules. International Finance, 3(2-July):273-86.

Mendoza EG, Oviedo PM (2004): Public Debt, Fiscal Solvency and Macroeconomic Uncertainty in Latin America: The Cases of Brazil, Colombia, Costa Rica, and Mexico. NBER Working Paper, no. w10637.

Miniane J (2004): Productivity Shocks, Learning, and Open Economy Dynamics. IMF Working Paper, no. 04/88.

Muth J (1960): Optimal Properties of Exponentially Weighted Forecasts. Journal of the American Statistical Association. 55(290-June):299-306.

Reinhart C, Rogoff K, Savastano M (2003): Debt Intolerance. Brookings Papers on Economic Activity,(1):1-62.

Rogoff K (2003): The IMF Strikes Back. Foreign Policy, 134(January/February):38-47.

Sargent TJ (1987): Macroeconomic Theory. 2nd Edition. Orlando, Florida, Academic Press.

Schmitt-Grohe S, Uribe M (2002): Optimal Fiscal and Monetary Policy Under Sticky Prices. NBER Working Paper, no. w9220.

Siu HE (2004): Optimal Fiscal and Monetary Policy with Sticky Prices Journal of Monetary Economics, 51(3-April):575-607.

Talmain G (1998): An Analytical Approximate Solution to the Problem of Precautionary Savings. Journal of Economic Dynamics and Control, 23:113-124.

Talvi E, Végh C (Eds.) (2000): Cómo Armar el Rompecabezas Fiscal: Nuevos Indicadores de Sostenibilidad. Washington, Inter-American Development Bank. 
Tanner E, Samake I (2008): Probabilistic Sustainability of Public Debt: A Vector Autoregression Approach for Brazil, Mexico, and Turkey. IMF Staff Papers, 55(1):149-182).

Woodford M (2001): Fiscal Requirements for Price Stability. Journal of Money, Credit, and Banking, 33(3-August):669-728. 